(bDMARDs) in respectively $67.4 \%$ and $30.6 \%$ of cases. Corticosteroids and Nonsteroidal Anti-Inflammatories (NSAIDs) intake was noted in 39.1 and $33.7 \%$ of patients.

Difficulties to access to rheumatologist care appointments were reported in $82.9 \%$ of the participants. Reasons of thoses difficulties are summurized in Figure 1.

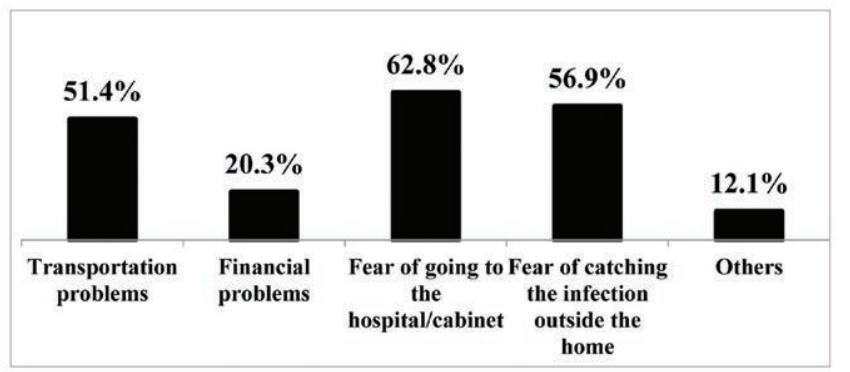

Figure 1. Causes of difficulties of access to Rheumatologist care during COVID-19 pandemic.

Half of patients declared that the pandemic had affected their therapeutic compliance. Discontinued drugs were in decreasing order: Synthetic antimalarials $(68.4 \%)$, NSAIDs (45.8\%), Methotrexate (43.8\%), bDMARDs (25.2\%), Sulfasalazine (18.2\%) and Corticosteroids (10,2\%).

Causes of treatments interruption are summarized in Table I.

Table 1. Causes of treatments interuption in patients with CIRD

\begin{tabular}{|c|c|c|c|c|c|}
\hline Drugs & $\begin{array}{l}\text { Not } \\
\text { found in } \\
\text { pharma- } \\
\text { cies }\end{array}$ & $\begin{array}{l}\text { The pharmacy } \\
\text { refuses to give } \\
\text { me the treatment } \\
\text { without a recent } \\
\text { prescription }\end{array}$ & $\begin{array}{l}\text { To avoid the } \\
\text { decrease in immu- } \\
\text { nity and therefore } \\
\text { to avoid catching } \\
\text { Covid-19 }\end{array}$ & $\begin{array}{l}\text { I stopped the } \\
\text { follow-up, } \\
\text { and so I } \\
\text { stopped the } \\
\text { treatment... }\end{array}$ & $\begin{array}{l}\text { Other } \\
\text { reasons }\end{array}$ \\
\hline NSAIDS & 0 & 27.8 & 74.1 & 44.4 & 27.8 \\
\hline Corticosteroids & 0 & 14.3 & 92.9 & 57.1 & 50 \\
\hline Methotrexate & 70.1 & 3 & 10.4 & 16.4 & 22.4 \\
\hline Sulfasalazine & 0 & 12.5 & 25 & 75 & 100 \\
\hline $\begin{array}{l}\text { Synthetic } \\
\text { antimalarial }\end{array}$ & 69.2 & 0 & 0 & 23.1 & 61.5 \\
\hline Leflunomide & 0 & 0 & 0 & 0 & 0 \\
\hline bDMARDs & 0 & 7.4 & 40.7 & 44.4 & 51.9 \\
\hline
\end{tabular}

Conclusion: The COVID-19 pandemic impacted heavly on therapeutic maintenance in CIRD patients in our country. Patients expressed many difficulties in access to appropiate management. Facing to all thoses consequences, we need to devolopp as soon as possible adequate solutions adapted in such health crisis, especially therapeutic education and telemedecine.

Disclosure of Interests: None declared

DOI: 10.1136/annrheumdis-2021-eular.4151

\section{AB0900-HPR THE EXPECTATIONS AND EXPERIENCES OF PATIENTS WITH RHEUMATOID ARTHRITIS AFTER ENROLLING INTO AN EDUCATIONAL PROGRAM. RESULTS FROM A MIXED STUDY APPROACH}

R. A. Castiblanco Montañez ${ }^{1}$, A. Arevalo Velandia ${ }^{1}$, J. D. Garzon Cepeda ${ }^{1}$, F. Rodriguez-Florido ${ }^{2}$, D. Buitrago-Garcia ${ }^{1}$, G. Sánchez ${ }^{1}$, P. Santos-Moreno ${ }^{2}$. ${ }^{1}$ Fundación Universitaria de Ciencias de la Salud FUCS. Sede Centro, Bogotá, Bogotá, Colombia; ${ }^{2}$ Biomab IPS, Bogotá, Bogotá, Colombia

Background: Rheumatoid arthritis (RA) is a high-cost disease, usually diagnosed at a productive age in life. RA brings significant changes in a patient's life. On an emotional level, the patient perceives a strong impact that generates disorientation, denial, depression, hopelessness, anger and fear due to the uncertainty of the development of the disease and the doubt of the turn that his life will take. However, each patient has different ways of coping with the disease and adapting to it $(1,2)$. These changes require attention from health personnel. In this regard, different studies have reported the effect of educational, support and empowerment programs for patients on reducing the effects of the disease and the benefits are oriented towards improving lifestyles by improving self-care $(3,4)$. Objectives: To describe the experience of patients with rheumatoid arthritis, their perception and expectations about entering a multicomponent educational program in a specialized center in Bogotá - Colombia.

Methods: For this study a concurrent mixed design was used, in which quantitative and qualitative methods are applied simultaneously, we invited patients with rheumatoid arthritis who attended a specialized center in Bogotá - Colombia who enrolled in an education program called UNIVERSITAR. The quantitative phase included a descriptive analysis and the application of the expectations scale adapted from Borkovec and $\mathrm{Nau}(5)$; this scale collects information about the level of expectations and satisfaction of the program. The scale ranges from 0 (not at all) to 10 (very much). Immediately after the application of the scale, the participants were invited to a focus group that allowed the dialogue on the perception and expectations of the participants regarding the program, through a dynamic process in which the participants exchanged their ideas and opin ions. A group interview script was used, aimed at identifying the patients' experiences with their diagnosis and their expectations regarding the program. Two focus groups were held with an average duration of one hour; the discussion was recorded on audio and transcribed in its entirely.

Results: We included 31 participants and were distributed in two focus groups The median age of the participants was 60 years IQR (54-67), 92\% were female. $77 \%$ of participants reported high scores for the satisfaction regarding the program. In the qualitative phase two categories emerged that speak of the experience of the participants with the disease. They highlighted the appearance of this disease in their lives in an unexpected way, the doubts and uncertainties that were generated from the diagnosis and the implications that this condition causes health in their everyday life. However, in the second category, the expectations and motivations of the participants towards the educational program are highlighted, and the factors that influence their participation and their motivation to train and empower themselves to make decisions and as expert patients, capable of educate, guide and support other patients with the same diagnosis. Conclusion: The expectations and perceptions of the patients are of great importance, since through these the conditions with which these educational programs provide interventions and a better quality of life to these patients can be improved. Disclosure of Interests: None declared

DOI: 10.1136/annrheumdis-2021-eular.4160

\section{AB0901-HPR SOCIAL AND PSYCHOLOGICAL IMPACT OF THE CONTAINEMENT DURING COVID-19 PANDEMIC ON PATIENTS WITH CHRONIC INFLAMMATORY RHEUMATIC DISEASES}

T. El Joumani ${ }^{1}$, H. Rkain ${ }^{1}$, T. Fatima Zahrae ${ }^{1}$, H. Kenza ${ }^{2}$, A. Radouan ${ }^{3}$, N. Laila ${ }^{4}$, S. Bahloul ${ }^{1}$, E. A. Nada ${ }^{1}$, T. Latifa ${ }^{1}$, N. Hajjaj-Hassouni ${ }^{5}$, F. Allali ${ }^{1}{ }^{1}$ El Ayachi Hospital, Faculty of Medicine and Pharmacy of Rabat, Mohammed V University, Rabat, Morocco, Department of Rheumatology B, Rabat, Morocco; ${ }^{2}$ Université Mohammed VI des Sciences de la Santé- UM6SS, Casablanca, Morocco., Ecole Internationale de Santé Publique, Rabat, Morocco; ${ }^{3}$ Faculty of Medicine and Pharmacy of Rabat, Mohammed V University, Rabat, Morocco, Laboratory of Biostatistics, Rabat, Morocco; ${ }^{4}$ Moroccan Association of Patients With Rheumatoid Arthritis and Spondyloarthritis, Rheumatology, Rabat, Morocco; ${ }^{5}$ International University of Rabat, Rabat, Morocco, Rheumatology, Rabat, Morocco

Background: Covid-19 pandemic had a worldwide impact on the population global economy and health care systems.

Objectives: To evaluate the psychological state and social impact of patients with Chronic Inflammatory Rheumatic Diseases (CIRD) during this pandemic in order to understand how to optimize their quality of life.

Methods: It's a cross-sectional survey, where the data were collected through the online survey tool "google forms". A pilot test were conducted with the study committee members who analyzed the apparent validity of the questionnaire and identified issues that could lead to misunderstandings, and their suggestions were refined by a retest reliability until general agreement.

The social and psychological impacts were evaluated by 14 questions exploring the different effects of the containment on negative feelings, interest in the family, changes in daily activities and plans, quality of sleep, practice of physical activity before and during containment, as well as the impact of the Coronavirus on psychological health. Statistical Analysis System IBM SPSS Statistics V20.0.0 was used to analyze the survey data.

Results: 350 patients had participated in this online survey (mean age of 46,1 $\pm 14,4,68 \%$ were women, $15.7 \%$ were illiterate, $45.7 \%$ were unemployed, rural residence in $11.7 \%$ of cases).

Patients reported that their mental health has been negatively affected by Coronavirus in $59.1 \%$ of cases. Table 1 summarizes the psychological events during the containment.

Table 1. Negative feelings during the containment

\begin{tabular}{lc}
\hline Negative feelings (\%) & $\mathrm{N}=\mathbf{3 5 0}$ \\
\hline Hopelessness & 23.7 \\
Anxiety & 55.4 \\
Fear & 29.7 \\
Frustration & 22.9 \\
Loneliness & 17.4 \\
Anger & 22.6 \\
Powerlessness & 24.3
\end{tabular}

Patients reported that they paid more attention to their family in $87.1 \%$ during containment. Their daily lives and their life plans had changed because of 